International Journal of Management Science and Business Administration

Volume 3, Issue 5, July 2017, Pages 50-54

DOI: 10.18775/ijmsba.1849-5664-5419.2014.35.1006

URL: http://dx.doi.org/10.18775/ijmsba.1849-5664-5419.2014.35.1006

\title{
Business Process Management in Financial and Non-Financial Institutions: Payment Process Modelling in Financial Flows Management
}

\author{
Sardor Umurzakov \\ Researcher, Tashkent State University of Economics, Uzbekistan
}

\begin{abstract}
Business process management is a progressively developing area of science, which is seen as the most modern and forward-looking innovative. Modern business operations remain highly dependent on IT solutions to steer the processes. Business process management solutions have been the clue for easing daily business operations. IT solutions have actively penetrated the working environment in all areas of business, especially the financial sector. It is beyond to imagine modern financial markets and institutions without IT software support. Not only billing, calculation and payment processes, even stock pricing, market analysis and risk monitor tools are fully computerized through business process modeling. This article studies the current role of business process management in the sample of internal payment and transaction in non-financial and financial firms.
\end{abstract}

Keywords: Business process management, Payment, Financial organizations.

\section{Introduction}

Globalization and competitive pressure urge many organizations to radically change business processes (Hlupic and Robinson, 1998). Changing the face of a global business environment and new organizational structures of enterprises require regular developments in business process management solutions. Emerging promising industries and expansion of business models with innovative origins put business solutions providers under a serious challenge of keeping pace with developments in business processes. Apart from the common importance of adapting to innovative business climate, there are country-specific aspects which need a particular approach in modeling the business process and setting management characteristics.

Advancement level of business practices differs across countries. Systemic differences, regular structural changes, reforms, and modernization often drive the factors of striking distinguishing features in business conduct and management. Decision making, stability provision, and monitoring measures take roots from prudently and appropriately structured business process management. Advanced business environment relies on solid and up-to-date business process management owing to the high concentration of leading businesses, particularly in developed countries. Organizations in developing countries possess comparatively differentiating attributes of processes in the workflow.

Business process management is an integrated approach towards the alignment of information systems with business requirements (Šperka, 2017). The new era of advancement in technology and business, information technology gained a broad access to business environment at international, national and enterprise-levels. Being rooted from quality management and business modeling practices, business process management remained as a key tool for conducting business with sophisticated monitoring, analysis and optimization instruments. Nowadays it embraces the entire cycle of processes, ranging from modeling to automation, from monitoring to strategic decision making.

Business process management is of utmost relevance in the modern business community. Depending on the expansion level, operating sector, location and market profile of an enterprise, business process management solutions may differ. 
Providers offer diverse models with particular flexibility tools or for specific industries/companies. Among advanced business process management models, enterprise model is marked with its flexibility and accessibility. Despite a large number of hybrid models in which enterprise model was a key element, modified ones have been facing considerable limitations in smooth functioning and compatibility due to lack of flexibility. The Capability Maturity Model, developed by Carnegie Mellon University, is believed as a high profile model which can serve as a roadmap and an efficient data flow management system. Modification of enterprise model with priority attributes of Capability Maturity Model can potentially be a good alignment of the hybrid model with fewer restrictions and more opportunities (Figure $1)$.

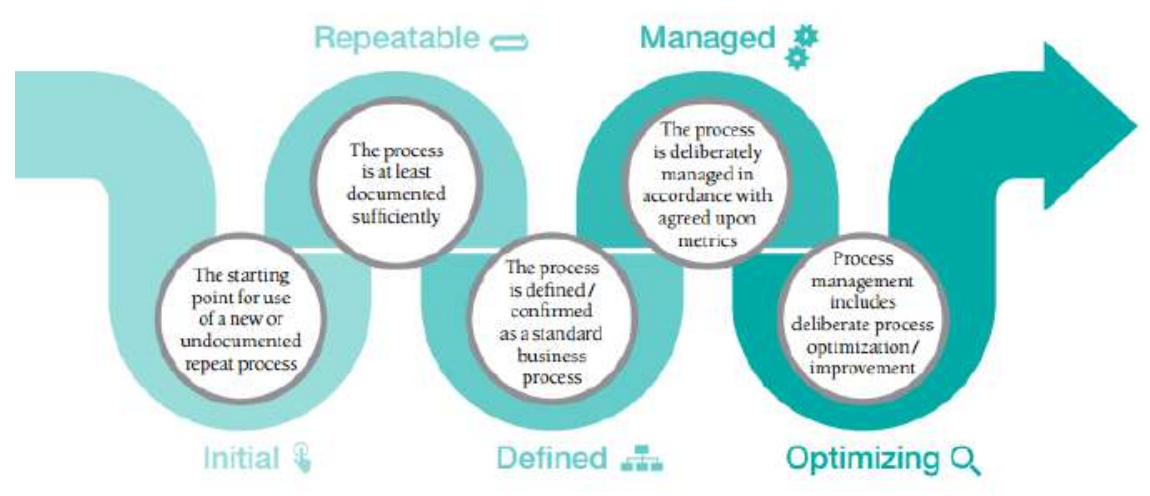

Figure 1: Capability Maturity Model

Source: Carnegie Mellon University, 2013

At the organization level, enterprise model fully functions as an entire process management monitor. However, at country-level, it may lack the most relevant capabilities especially in treasury system, the internal financial data flow of chain organizations, supply chain, and warehouse management. In order to ensure the compatibility and flexibility, we attempted to create an optimal mixture of business process management with five key attributes of Capability Maturity Model. But financial organizations differ in intangible output and business processes. In turn, financial organizations are divided into several types: insurance, bank, non-bank and financial authorities such as central banks and public financial organizations. Although they are in the same bunch, working process and operations are totally different. In this paper, we study the financial flow management modeling in banks, the beneficiary organization of government budget and a firm operating in non-financial industries by using particular elements of Capability Maturity Model in payment process modeling.

\section{Literature Review}

Business process management is an area of joint scientific partnership among academicians, business rounds, managers and IT professionals. Large scale research and experimental applications made business process management a subject of hot research interest. Among leading research, simulation of business processes was of central interest. In 1998, Hlupic and Robinson investigated the potential of simulation modeling to be used for modeling business processes and supports the case for a wider use of simulation techniques by the business community. Gordijn, Akkermans and van Vliet (2000) analyzed the expansion of e-business through IT-based business process management solutions. In their research, a group of authors differentiated the business process modeling and business process management in terms of added-values, and they explained the consequences of misunderstanding of these two terms. Kalpic and Bernus (2002) examined the power of business process management in new product development by re-engineering the product development, functional, decisional, and organizational management. They reinvestigated the opportunities and ability of business process management in a new era of IT development and modern business operations. The fast growing business process modeling techniques and tools led to the emergence of diverse products in different quality. In 2000 , Hommes and van Reijwoud studied the development of a framework for understanding the quality of business process modeling techniques, called the Q-ME framework. Their framework defined the elements that constitute a modeling technique and presents a number of quality properties as well as ways to operationalize them. 


\section{Organizational behaviour of an enterprise and payment process modelling}

Even at the stage of the conceptual design of the information system based on the modeling of business processes, it is possible to envisage all the most important interrelationships of the financial flow management system. This is, in particular, an organizational chart consisting of blocks denoting certain elements of the business process, and lines of relationships that indicate the sequence of their implementation (Figure 2). Figure 2 illustrates a typical model of business processes for managing financial flows in a financial organization and a beneficiary of budget funds, which reflects the sequence of actions. Initially, the sender of payment prepares an invoice which specifies its main attributes: counterparty, banking account, budget classification item. After that, the owner of the budget examines and signs the application, which is then transferred to the territorial office of the treasury. It is introduced into the accounting system which receives the status of "Application for Payment" and is automatically sent to the central treasury.

Similarly, the cash flow management system interacts with the inventory system at the level of integration, which allows you to create an application for payment according to the invoice data in an accelerated mode. After that, all the entries receive the status "Blank", which already allows them to be viewed, but does not yet enable payment, since an application must contain a planned execution date-payment. In the future, applications are subject to budgetary control, which confirms the possibility of their payment, and only then they are put on payment. In the case of budgetary control, the compliance of an application with the fixed funding limit is checked and if it does not meet this requirement, then budget control does not permit to make the transaction. In this case, the application is given the status of a lack of a limit and it is sent for additional coordination and identification of the source of funding. Along with this, applications that have successfully passed budget control are considered by the Treasury and get the status "For Payment".



Figure 2: Sample model of payment and transaction process

Source: Umurzakov, 2017. 
They are automatically entered in the payment schedule for the next week and approved by the company's chief financial officer. In the subsequent analysis of the generated schedule, cash gaps can be identified, and therefore, the person responsible for the schedule has the right to make decisions on transferring certain payments to another date. According to the "bank-client" system, payments are made only on applications that have the status "For Payment". After that, the information on already made payments goes to the accounting system, where they are compared with applications that have the status "for payment". Then the accounting department carries out account statements that automatically enter the central treasury, which, based on the information received, analyses all company payments for a certain period of time.

On the basis of the design of the information system, many models are created, each of which characterizes the system in a certain aspect. It is primarily aimed at subsequent use with its hardware and software implementation at the level of a working project. In some cases, completing the design stage, reviewing and streamlining the generated system of models, and also establishing possible relationships for the convenience of its further use is a kind of tool for generating the entire automated complex. To achieve this, the developers of a particular system create a so-called integrated model that, in a formalized form, contains a description of all the characteristics of the system being designed, and also determines the criteria for a system approach to the formation of the information and software product that is created. It indicates the basic interrelations of its elements.

Along with other components, the specificity of each of the possible models of the projected system is characterized as follows:

- a certain set of elements of a particular model;

- $\quad$ presence and regularities of the interrelationships of the elements presented;

- $\quad$ parameters that describe the essence and state of the information system;

- the originality of the model and its architectonics.

An integrated model, consisting of classification blocks, characterizes the entire information system, and also contains a brief description of their interrelationships. From this, it becomes clear that the integration of the listed components, their specific set, representing a dialectical unity of form and content, create an exclusive model that fully corresponds to a specific, objectively existing automated system. Taking into account the methods of organizational systematics, which is now actively implemented in the design of automated systems, should be quite high. It is due to the level of organizational support of the system which based on the implementation of certain regulations.

Thus, the integrated model allows both to assess the completeness and content of the design process, and to remove possible defects before moving to machine implementation when the introduction of amendments to the project is already associated with significant organizational and financial costs. Meanwhile, the design and content of the information model blocks are defined jointly by the system developers with the customer, on the basis of which its already agreed version serves as the initial specification for the formation of the technical task for the development of technical and working projects of the financial flow management system.

\section{Conclusion}

To achieve the potential value of business process management, organizations must first create the conditions for success. That means securing and using senior sponsorship, rigorously defining organization-wide strategic objectives and a business case, and putting in place the right governance structures and the appropriate technology. The business process management must be purposefully managed throughout to ensure that the intended benefits are realized and communicated. Budgets and resources may need to be integrated and/or centralized to achieve wider reach. C-level commitment and strong change management skills are essential to bring about the required cultural change, including the move to greater cross-functional collaboration. Under the right conditions, business process management can deliver exceptional value that more than justifies the effort involved, as the experience of early adopters confirms. 


\section{References}

- Aguilar-Saven, R. (2003). Business process modeling: review and framework. International Journal of Production Economics. Issue 90. pp-129-149.

- Hommes, B. and Van Reijwoud, V. (2000). Assessing the quality of business process modeling techniques. The 33rd Hawaii International Conference on System Sciences. Hawaii. US. Crossref

- Kaplic, B., and Bernus, P. (2002). Business process modeling in industry - powerful tool in enterprise management. Computers in Industry. Issue 47. pp-299-318.

- Koubarakis, M. and Plexousakis, D. (2002). A formal framework for business process modeling and design. Information Systems. 27/2002. pp.299-319. Crossref

- Melao, N. and Pidd, M. (2000). A conceptual framework for understanding business processes and business process modeling. Information Systems Journal. $\underline{\text { Crossref }}$

- Russell, N., ter Hofstede, A., Van der Aalst, W., and Wohed, P. (2006). On the suitability of UML 2.0 activity diagrams for business process modeling. in: conceptual modeling 2006: Proceedings of APCCM2006, 16-19 January 2006, Australia, Tasmania, Hobart.

- Wetzstein, B. et al. (2007). Semantic business process management: a lifecycle based requirements analysis. Proceedings of the Workshop on Semantic Business Process and Product Lifecycle Management (SBPM 2007). Innsbruck, Austria. 